\title{
A Review of Systemic Lupus Erythematosus (SLE): Symptoms, Risk Factors, Treatment, and Health Related Quality of Life Issues
}

\author{
Sarah N. Al-Gahtani \\ Department of Internal Medicine, King Fahd Medical City, Riyadh, Saudi Arabia \\ Email: S_algahtani@live.com
}

How to cite this paper: Al-Gahtani, S.N. (2021) A Review of Systemic Lupus Erythematosus (SLE): Symptoms, Risk Factors, Treatment, and Health Related Quality of Life Issues. Open Journal of Rheumatology and Autoimmune Diseases, 11, 115-143. https://doi.org/10.4236/ojra.2021.114014

Received: August 5, 2021

Accepted: September 13, 2021

Published: September 16, 2021

Copyright $\odot 2021$ by author(s) and Scientific Research Publishing Inc. This work is licensed under the Creative Commons Attribution International License (CC BY 4.0).

http://creativecommons.org/licenses/by/4.0/

\begin{abstract}
In this paper, we present a thorough review of one of the most life-threatening autoimmune diseases, Systemic lupus erythematosus (lupus). Symptoms, risk factors, including genetic and epidemiological factors are discussed. Treatment, life expectancies, and Health Related Quality of Life of patients with SLE will be discussed as well. Special attention will be given to Lupus Nephritis.
\end{abstract}

\section{Keywords}

Autoimmune Disorders, Systemic Lupus Erythematosus, Environmental Risk Factors, Familial Aggregation, Lupus Nephritis, Treatment of SLE, Health Related Quality of Life

\section{Introduction}

Autoimmune system disorders cause abnormally low activity or overactivity of the immune system. In cases of immune system overactivity, the body attacks and damages its own tissues (autoimmune diseases). Immune deficiency diseases decrease the body's ability to fight invaders, causing vulnerability to infections. In response to an unknown trigger, the immune system may begin producing antibodies that instead of fighting infections, and attack the body's own tissues. When the immune system determines that healthy cells are foreign, it begins to produce antibodies to fight off the healthy cells. It is believed to be the source of an illness or infection. When an autoimmune disease is suspected, a rheumatologist will administer tests to determine what antibodies are being produced. Treatment for autoimmune diseases generally focuses on reducing immune sys- 
tem activity. Examples of autoimmune diseases include Systemic lupus erythematosus (lupus). Lupus is defined as an inflammatory disease in which the body's immune system attacks its own tissues and organs. The result of this hyperactive immune system is inflammation, swelling, and damage to the joints, skin, kidneys, blood, heart, and lungs. For some people, the symptoms of lupus are relatively minor. For others, the disease leads to lifelong disability. People with lupus develop autoimmune antibodies that can attach to tissues throughout the body. The joints, lungs, blood cells, nerves, and kidneys are commonly affected by lupus. Treatment often requires daily oral prednisone, a steroid that reduces immune system function. Lupus nephritis occurs when lupus autoantibodies affect structures in your kidneys that filter out waste. This causes kidney inflammation and may lead to blood in the urine, protein in the urine, high blood pressure, impaired kidney function or even kidney failure. In this review, we shall discuss history of the disease, symptoms, risk factors including genetics, treatments, and quality of life and treatment of SLE with special emphasis on lupus nephritis. We provide a flowchart for the plan of work in the Appendix.

\section{History of Lupus}

In a seminal paper by Smith and Cyr [1] (1988), the history of lupus was divided into three periods, classical, neoclassical, and modern. In this section we summarize the medical research history to uncover the mystery of this autoimmune disease.

\subsection{Lupus in the Classical Period (1230-1856)}

The authors of this important article by Smith and Cyr identified the term "lupus" (Latin for "wolf") which was used to describe erosive facial lesions that were reminiscent of a wolf's bite. The reader is referred to the list of references in the paper. The lesions now referred to as discoid lupus were described in (1833) by Cazenave [2] under the term "erythema centrifugum," while the butterfly distribution of the facial rash was noted by Von Hebra in (1846) [3].

\subsection{Lupus in the Neoclassical Period (1872-1948)}

The Neoclassical era of the history of lupus began in 1872 when Kaposi [4] first described the systemic nature of the disorder. He proposed that there were two types of lupus erythematosus; the discoid form and a disseminated (systemic) form. Furthermore, he enumerated various signs and symptoms which characterized the systemic form of the disease.

The existence of a systemic form of lupus was firmly established in (1904) by the work of Osler [5] in Baltimore and Jadassohn in Vienna [6]. Over the next thirty years, pathologic studies documented the existence of nonbacterial verrucous endocarditis (Liebman-Sacks disease) and wire-loop lesions in individuals with glomerulonephritis; such observations at the autopsy table led to the construct of collagen disease proposed by Klemperer and colleagues [7] in 
(1941). This terminology, "collagen vascular disease," persists in usage more than seventy years after its introduction.

\subsection{Lupus in the Modern Era (1948-Present)}

The most important discovery which characterized the modern era was the discovery of the LE cell by Hargraves and colleagues [8] in (1948). The investigators observed these cells in the bone marrow of individuals with acute disseminated lupus erythematosus and postulated that the cell "...is the result of... phagocytosis of free nuclear material with a resulting round vacuole containing this partially digested and lysed nuclear material..."

This discovery ushered in the present era of the application of immunology to the study of lupus erythematosus; it also allowed the diagnosis of individuals with much milder forms of the disease. This possibility, coupled with the discovery of cortisone as a treatment, changed the natural history of lupus as it was known prior to that time.

Two other immunologic markers were recognized in the 1950s as being associated with lupus: the biologic false-positive test for syphilis and the immunofluorescent test for antinuclear antibodies. Moore [9], working in Baltimore, demonstrated that systemic lupus developed in 7 percent of 148 individuals with chronic false-positive tests for syphilis and that a further 30 percent had symptoms consistent with collagen disease.

\subsection{The Development of Animal Model}

Two other major advances in the modern era have been the development of animal models of lupus and the recognition of the role of genetic predisposition to the development of lupus [10]. The mouse model has provided many insights into the immunopathogenesis of autoantibody formation, mechanisms of immunologic tolerance, the development of glomerulonephritis, the role of sex hormones in modulating the course of disease, and evaluation of treatments including recently developed biologic agents such as anti-CD4, among others.

\section{Signs and Symptoms of Lupus}

Lupus can affect almost any organ in your body. The symptoms of lupus also differ from person to person [11] [12] [13]. For example, one woman with lupus may have swollen knees and fever. Another woman may be tired all the time or have kidney trouble. Someone else may have rashes. Over time, new symptoms may develop, or some symptoms may happen less often.

Lupus symptoms also usually come and go, meaning that you don't have them all of the time. Lupus is a disease of flares, and remissions (the symptoms improve, and you feel better).

Lupus symptoms include:

- Muscle and joint pain. You may experience pain and stiffness, with or without swelling. This affects most people with lupus. Common areas for muscle 
pain and swelling include the neck, thighs, shoulders, and upper arms.

- Fever. A fever higher than 100 degrees Fahrenheit affects many people with lupus. The fever is often caused by inflammation or infection. Lupus medicine can help manage and prevent fever.

- Rashes. You may get rashes on any part of your body that is exposed to the sun, such as your face, arms, and hands. One common sign of lupus is a red, butterfly-shaped rash across the nose and cheeks.

- Chest pain. Lupus can trigger inflammation in the lining of the lungs. This causes chest pain when breathing deeply.

- Hair loss. Patchy or bald spots are common. Hair loss could also be caused by some medicines or infection.

- Sun or light sensitivity. Most people with lupus are sensitive to light, a condition called photosensitivity. Exposure to light can cause rashes, fever, fatigue, or joint pain in some people with lupus.

- Kidney problems. Half of people with lupus also have kidney problems, called lupus nephritis. Symptoms include weight gain, swollen ankles, high blood pressure, and decreased kidney function.

- Mouth sores. Also called ulcers, these sores usually appear on the roof of the mouth, but can also appear in the gums, inside the cheeks, and on the lips. They may be painless, or you may have soreness or dry mouth.

- Prolonged or extreme fatigue. You may feel tired or exhausted even when you get enough sleep. Fatigue can also be a warning sign of a lupus flare.

- Anemia. Fatigue could be a sign of anemia, a condition that happens when your body does not have red blood cells to carry oxygen throughout your body.

- Memory problems. Some people with lupus report problems with forgetfulness or confusion.

- Blood clotting. You may have a higher risk of blood clotting. This can cause blood clots in the legs or lungs, stroke, heart attack, or repeated miscarriages.

- Eye disease. You may get dry eyes, eye inflammation, and eyelid rashes.

Lupus flare. Flare is defined by International Consensus as a measurable increase in disease activity in one or more organ systems involving new or worse clinical signs and symptoms and/or laboratory measurements. Flares have been associated with more hospitalizations [14] and more organ and system damage, which in turn can lead to poorer prognosis and increased mortality [15] [16] [17]. In addition, the prolonged use of CS in the presence of persistence of disease or during flares can contribute to damage [18]. Flares, damage, and prolonged use of CS can contribute to poor health-related quality of life. Therefore, flare prevention is an important treatment goal in patient management. Understanding the pattern of flares in SLE patients would be informative not only in the day-to-day management of these patients, but also in the interpretation of clinical trials of new medications where frequency and type of flares are included as outcome measures. 


\section{Risk Factors for SLE}

Scientists divide risk factors associated with SLE into three groups; environmental, we divide the risk factors for Lupus into two groups; the first is related to environmental and the other is genetic factors.

\subsection{Environmental Risk Factors}

Aggregate data from population base studies reported that approximately $90 \%$ of patients with SLE are female, and the incidence of SLE among African Americans is increased 3 - 4-fold compared with that among Caucasians [19] [20]. It is therefore postulated that gender is a non-modifiable risk factor of prime importance.

There is strong epidemiologic evidence linking environmental factors, including current cigarette smoking, vitamin D level infections such as Epstein-Barr virus, dietary factors. In the following section we list some of these environmental risk factors.

\section{Cigarette Smoking}

Mechanistic evidence exists implicating smoking in SLE pathogenesis. Exposure to toxic components from cigarette smoke (e.g. tars, nicotine, carbon monoxide, polycyclic aromatic hydrocarbons and free radicals) can induce oxidative stress and directly damage endogenous proteins and DNA, leading to genetic mutations and gene activation, which could be involved in development of SLE [19]. Cigarette smoking stimulates the expression of CD95 on B and CD4 T cell surfaces, potentially inducing autoimmunity [20], and augments production of pro-inflammatory cytokines [21]. In a retrospective case-control study of SLE patients, current smokers were significantly more likely to have anti-double stranded DNA antibodies compared to never smokers [21]. Additionally, smoking leads to the formation of immunogenic DNA adducts with a half-life of 9 to 13 weeks, which may explain why current smoking has been more strongly associated with increased SLE risk [21]. However, two additional case-control studies performed since then have demonstrated an elevated risk for both current and former smokers compared to never smokers [22] [23].

\section{Vitamin D}

Further complicating our understanding of the relationship between UV radiation and SLE pathogenesis is the controversial role of Vitamin D. While exposure to solar UV radiation may trigger SLE disease flares, UV light exposure is also the main source of vitamin D production [24]. Vitamin D may be immunosuppressive once metabolized to $1 \alpha, 25(\mathrm{OH})_{2} \mathrm{D}$, and it has been suggested that UV-B radiation could reduce SLE risk via stimulation of cutaneous vitamin D synthesis [25]. Many cross-sectional and case-control studies have reported low 25(OH) vitamin D concentrations in SLE patients compared to controls, however, it is not clear whether low vitamin $\mathrm{D}$ is a cause or consequence of chronic disease.

\section{Infections}

(EBV) seropositivity rates are much higher in adults and children with SLE 
than age-matched controls [26]. Potential mechanisms involve Epstein-Barr virus protein complexes inducing type 1 interferon via Toll-like receptor 3 and molecular mimicry between EBV and SLE antigens [27]. Additionally, SLE patients have impaired CD8+ cytotoxic T cells, and irregular cytokine production in plasmacytoid dendritic cells and CD69+ CD4+ T cells in response to EBV. However, no conclusive data have established that EBV infection is linked to future risk of SLE. Notably, in a large population-based Danish cohort, EBV-serologic negative individuals had a sustained increased risk for SLE highest in the 1 to 4 years after testing (standardized incidence rate, 6.6; 95\% CI, 3.3 - 13.2), but this finding may have been due to a surveillance bias as EBV testing is likely to be performed during the work-up for early SLE symptoms [28]. In that study, no associations were found with EBV serologic positivity, infectious mononucleosis, or severe infectious mononucleosis requiring hospitalization [28] [29]. Therefore, the association between EBV and incident SLE, in particular the question of causality, remains to be fully elucidated.

\section{Air Pollution}

Particulate air pollution has effects like those of inhaled cigarette smoke and silica on the immune system and has been linked to asthma, chronic bronchitis, cardiovascular disease, and lung and laryngeal cancers [30] [31].

\section{Heavy Metals}

Data from experimental studies suggest that heavy metals may increase systemic autoimmunity, and that co-exposure to certain heavy metals may increase the risk associated with other exposures [32]. Mercury-exposed gold miners were demonstrated to have a higher prevalence of detectable ANA as compared to diamond and emerald miners with no occupational mercury exposure [33].

Dietary Factors and Medications

While there are very few prospective studies of dietary intake and SLE, several lines of evidence implicate dietary factors in SLE pathogenesis. First, murine models suggest that dietary exposures can induce epigenetic changes and SLE autoimmunity [34] [35]. When genetically-SLE predisposed C57BL/6 $\times$ SJL mice were fed methyl donor poor diets, they developed lupus nephritis, whereas those fed diets rich in methyl group micronutrients did not [36] [37] [38]. As oxidative stress, inflammation and cytokine dysregulation are central to SLE pathogenesis, diet may play an important accelerating role. Prior studies suggest that high intake of certain antioxidants; fish, olive oil and cooked vegetables may confer a protective effect against chronic disease development [38]. Women consuming > $200 \mathrm{~mL}$ of coffee per day had increased inflammation markers, such as interleukin-6 and tumor necrosis factor- $\alpha$, compared with coffee non-drinkers [38]. A prior case-control study suggests a significant increased SLE risk with black tea consumption and borderline increased risk with coffee consumption, but not green tea [38].

\subsection{Genetic Risk Factors}

During the past few years extensive research on the genetic bases of SLE has 
emerged. Genetic variation was first shown to be important in SLE in the 1970s with associations in the human leukocyte antigen region. Almost four decades later, and with the help of increasingly powerful genetic approaches, more than 25 genes are now known to contribute to the mechanisms that predispose individuals to lupus [39]. Over half of these loci have been discovered in the past 2 years, underscoring the extraordinary success of genome-wide association approaches in SLE. Well-established risk factors include alleles in the major histocompatibility complex region (multiple genes), IRF5, ITGAM, STAT4, BLK, BANK1, PDCD1, PTPN22, TNFSF4, TNFAIP3, SPP1, some of the Fcg receptors, and deficiencies in several complement components, including $\mathrm{C} 1 \mathrm{q}, \mathrm{C} 4$ and $\mathrm{C} 2$. As reviewed here, many susceptibility genes fall into key pathways that are consistent with previous studies implicating immune complexes, host immune signal transduction and interferon pathways in the pathogenesis of SLE. Other loci have no known function or apparent immunological role and have the potential to reveal novel disease mechanisms. Certainly, as our understanding of the genetic etiology of SLE continues to mature, important new opportunities will emerge for developing more effective diagnostic and clinical management tools for this complex autoimmune disease.

In the past 2 years, a series of landmark studies have been reported that have revolutionized our understanding of the genetics of lupus. These are composed of insightful candidate gene studies and are anchored by genome-wide association (GWA) studies that include more than 10,000 individuals of European descent genotyped at over 300,000 single nucleotide polymorphisms (SNPs). Successful mapping of risk loci for lupus is comparable to inflammatory bowel disease where over 30 loci have now been identified [40]. SLE has long been considered a prototypic autoimmune disease, and from the genetics perspective, has served that title well. The coming years will most certainly continue to reveal additional associations, refinements to our current understanding of those established thus far and provide new clues to explain the clinical heterogeneity that is a hallmark of SLE. Additional work will include detailed genetic studies in multiple ethnic groups, the development of models of disease that incorporate environmental influences, and studies to determine the overlapping and unique relationships among genetic variants associated with other related autoimmune phenotypes. Every robust, authentic association has a compulsory role in pathogenesis, which promises to change profoundly our capacity to diagnose, predict and treat human disease [40] [41].

A recent paper [42] focusing on the Genome-wide association studies of Systemic Lupus Erythematosus (SLE) nominated 3073 genetic variants at 91 risk loci. To systematically screen these variants for allelic transcriptional enhancer activity, the authors construct a massively parallel reporter assay (MPRA) library comprising 12,396 DNA oligonucleotides containing the genomic context around every allele of each SLE variant. Collectively, their approach provided a blueprint for the discovery of allelic gene regulation at risk loci for any disease and offers 
insight into the transcriptional regulatory mechanisms underlying SLE.

\subsection{Genetic Epidemiology of SLE: Studies on the Familial Aggregation of SLE}

Family studies are the only design that helps quantifying the inheritance of SLE and its clustering among family members. Only a few studies have looked at familial aggregation of SLE on a nationwide level. In a recent cohort study from Taiwan, 18283 [43] persons were identified as having SLE. Among these, 607 first-degree relatives had SLE, corresponding to an overall 17 times increased risk of SLE in first-degree relatives and a 315 times increased risk in twins [43] [44]. The cohort was based on national health insurance data, where the insured person had to claim relatives as dependents. Hence, $20 \%$ of the cohort members were registered alone without any identifiable relative. However, the diagnosis of SLE could only be agreed upon by an expert panel from the Taiwan National.

The study [43] which is a nation-wide registry-based assessed the impact of having a family history of SLE on the risk of developing autoimmune-diseases (AD) in a population-based Danish cohort. The important findings were that the risk of developing any $\mathrm{AD}$ was significantly $51 \%$ and $28 \%$ elevated in individuals with a first-degree or second- or third-degree relative with SLE, respectively. The risk was substantially elevated for SLE, but also for RA, IBD, type 1 diabetes mellitus and the combined group of other ADs in individuals with an SLE-affected first degree relative. Individuals who had a co-twin or more than one first-degree relative with SLE were at a 76- and 61-times increased risk of developing SLE, respectively. There was no clear influence of the sex of the SLE-affected family member on the risk of SLE, although male cohort members with an SLE-affected male relative were at a 10 -fold elevated relative risk of developing SLE as compared with the 8 -fold increased risk in female cohort members. In one previous cohort study, there was a trend that men with SLE-affected male relatives were at a higher risk of SLE [44]. In summary, the study showed that a family history of SLE constitutes a major risk factor for subsequent development of SLE and other ADs in a manner that depends on the degree of relatedness. Our findings may be useful when counselling families affected by SLE. Many close family members of SLE patients may find it reassuring to learn that although their relative risk of developing SLE themselves is markedly elevated; their absolute risk remains low; according to the present national cohort study only around $2 \%$ of individuals with an SLE-affected non-twin first-degree relative developed SLE during an average of 22 years of follow-up.

Another population-based study on the familial aggregation of SLE has reported the Hazard of SLE and other AD. The study assessed the impact of having a family history of SLE on the risk of developing an AD in a population-based Danish cohort. We summarized and modified their findings in Table 1. We also calculated the correlation between the risk of SLE and that of AI for all family relations. The Pearson's correlation between the HR of SLE and the HR of AI 
Table 1. Familial aggregation of risk of SLE and other Auto-Immune (AI) system diseases.

\begin{tabular}{ccccc}
\hline Family relation & HR_SLE & HR_AI & P-SLE & p-AI \\
\hline MZT & $86.70(149.5)$ & $3.84(3.6)$ & 0.655 & 0.431 \\
DZT & $49.70(86.5)$ & $0.95(1.7)$ & 0.0001 & 0.972 \\
CHILD & $17.00(5.6)$ & $1.45(0.2)$ & 0.004 & 0.022 \\
SIB & $11.10(2.38)$ & $1.68(0.11)$ & 0.0001 & 0.0001 \\
PARENT & $8.72(1.3)$ & $1.44(0.06)$ & 0.0001 & 0.0001 \\
GRAND & $2.10(1.2)$ & $1.44(0.08)$ & 0.362 & 0.0001 \\
AUNT_UNC & $3.05(5.3)$ & $1.17(0.23)$ & 0.70 & 0.460 \\
HALF_SIB & $5.66(3.9)$ & $1.08(0.17)$ & 0.237 & 0.638 \\
N_NEPH & $4.57(2.3)$ & $1.06(0.1)$ & 0.116 & 0.516 \\
COUSIN & $5.16(4.8)$ & $1.22(0.2)$ & 0.391 & 0.265 \\
HALF_A_U & $4.75(8.3)$ & $1.35(0.17)$ & 0.650 & 0.207 \\
\hline
\end{tabular}

was 0.78 , which is highly significant. This high correlation underscores the relationship between Lupus and other autoimmune disorders, and their aggregation among family relatives.

\section{Lupus Nephritis}

Lupus nephritis (LN) occurs in $~ 50 \%$ of patients with SLE and is the most common, but not the only, cause of kidney injury in SLE. Men with SLE tend to have more aggressive disease with higher rates of renal and cardiovascular involvement and are more likely to develop kidney failure than women [45]. Patients with SLE who develop LN present at a younger age than patients with SLE without nephritis [46]. Additionally, LN typically develops early in the disease course, generally within the first 6 to 36 months, and may be present at initial diagnosis. Risk factors for the development of LN include younger age, male sex, and non-European ancestry. In the United States, the incidence of LN is higher in black (34\% - 51\%), Hispanic (31\% - 43\%), and Asian (33\% - 55\%) compared with white $(14 \%-23 \%)$ patients. Black and Hispanic patients have worse outcomes and are more likely to progress to kidney failure than white patients. Black and Hispanic patients tend to have more severe underlying histopathology, higher serum creatinine levels, and more proteinuria than white patients at LN diagnosis. Additionally, autoantibodies strongly associated with LN, including anti-Sm, anti-Ro, and anti-ribonucleoprotein antibodies, are more frequently positive in black compared with white patients. The reasons for these racial and ethnic differences are not completely understood, but genetic and socioeconomic factors likely contribute Mortality associated with lupus is significantly higher in those with LN compared with those without LN, and death directly attributable to kidney disease occurs in $5 \%$ to $25 \%$ of patients with proliferative LN within 5 years of onset. Furthermore, $10 \%$ to $30 \%$ of patients with LN progress 
to kidney failure requiring kidney replacement therapy (KRT). Patients with proliferative forms of LN (class III, IV, or III/IV + V) are at highest risk for requiring KRT. Achieving a complete clinical response to treatment is critical to preserving long-term kidney health. In one study, patients who achieved a complete clinical response had $92 \%$ kidney survival at 10 years compared to $43 \%$ in partial responders and $13 \%$ in non-responders. Overall, the kidney failure risk associated with LN improved from the 1970s to 2000. However, since 2000, the rate of $\mathrm{LN}$ requiring KRT has remained consistent and there is evidence to suggest that these rates are increasing now, particularly in black populations.

Genetic and environmental factors play important roles in the pathogenesis of SLE [45] [46]. The incidence and prevalence of SLE is higher in non-European ancestry, especially in African ancestry. The severity of SLE also varies among the ethnic groups, being more severe in non-European populations [47] [48] [49]. Supporting a genetic contribution to disease, monozygotic twins are much more likely to be concordant for SLE than dizygotic twins (concordance rate $24 \%$ and $2 \%$, respectively) [50]. Familial aggregation of SLE has also been clearly documented, and most pedigrees support a non-Mendelian complex inheritance [51]. These facts strongly support notion of a polygenic genetic contribution to SLE pathogenesis.

Among the various organ manifestations of SLE, lupus nephritis (LN) is one of the most feared, potentially resulting in organ damage and renal insufficiency those results in poor clinical outcomes despite recent improvements in SLE treatment.

Genome-Wide-Association Studies (GWAS) and candidate gene association studies have revealed numerous risk genes for SLE, including loci which contain genes that function in the innate and adaptive immune system [52] [53]. Some of these genes are also closely associated with LN. However, most of these previous studies were not primarily focused on the nephritis phenotype, and less is known about which genes predispose to LN. Some recent studies which have focused on identifying the genes specifically responsible for LN have identified intrarenal genes that are associated with LN, but not associated with the susceptibility of SLE in general [54] [55]. While the exact functional mechanisms of these renal-related candidate genes remain unclear, it seems that the genetic basis of LN involves a combination of general SLE susceptibility genes which function in the immune system and genes which are more renal-specific that predispose specifically to $\mathrm{LN}$.

\subsection{Difference in Incidence Rate and Severity of LN between Ethnicities}

Among various organ manifestations of SLE, LN is one of the most severe, and can progress to end-stage renal disease (ESRD) leading to increased morbidity and mortality. LN affects about $40 \%$ of SLE patients throughout their lifetime [56]. Despite recent advances in treatment, patients with LN still have higher morbidity and mortality compared with those without LN [56] [57] [58]. It is 
well known that African, Asian, and Hispanic populations are more likely to develop LN as compared to European ancestry [48] [56] [59] [60] [61]. There are also differences in severity of LN among the ethnicities, with LN being more severe in non-European populations [48] [56]. This disparity between ancestral backgrounds could be related to genetic or environmental factors [62]. To investigate the importance of genetic factors, Sanchez et al. conducted a study evaluating the genetic impact of the proportion of Amerindian vs. European genetic ancestry in admixed populations living in South America. This is an informative way to study the contribution of genetics to LN with some control over environment, as different individuals living in the same population and same location will have different proportional genetic ancestry. This study revealed that an increased proportion of Amerindian genetic ancestry correlated with increased risk of developing LN [47]. Another study demonstrated familial clustering of ESRD African ancestry SLE patients with LN, suggesting shared genetic factors contributing to LN in these families [63]. These studies support the idea that genetic factors contribute to the pathogenesis of LN.

Not only genetic changes, but epigenetic changes (i.e., post-translational modifications) also play an important role in the pathogenesis of SLE. DNA methylation is one of the important post-translational regulatory modifications, typically occurring at CG dinucleotides. DNA methylation results in gene silencing by tightening the chromatin structure and limiting the access of transcriptional factors, while DNA hypomethylation induce transcription of genes.

Impaired DNA methylation status in CD4+ T cells of SLE patients was reported more than 20 years ago [64] [65] [66]. As next-generation sequencing technology has advanced, genome-wide methylation studies have demonstrated the differences in methylation profiles of CD4 T cells in SLE patients compared to those of healthy controls. Some studies have shown a difference in methylation profiles between different groups of SLE patients [67] [68]. Of note, hypomethylation of type I IFN-regulated genes known to play important roles in the pathogenesis of SLE are reported in SLE patients [69] [70]. More recently, Coit et al. [70] identified that there are more robust differences in methylation status of type I IFN-regulated genes when compared between SLE patients with LN and SLE patients without LN [71].

These studies shed light to another aspect of genetic involvement in the pathogenesis of SLE and LN, although there is still much work to be done to clarify their specific role to LN and take advantage of this knowledge to design treatments.

\subsection{Trend in Mortality of Patients with Lupus Nephritis}

A recent study on the survival rate of patients with renal diseases reported very important findings from a community-based study [72]. The rates of renal survival (i.e., survival without dialysis) in patients with lupus nephritis in the 1990s ranged from $83 \%$ to $92 \%$ over 5 years of follow up and from $74 \%$ to $84 \%$ over 10 years of follow up [73] [74] [75]. The risk of end-stage renal disease (ESRD) has 
been particularly high in patients with diffuse proliferative glomerulonephritis, with risk estimates ranging from $11 \%$ to $33 \%$ over 5 years of follow up [76] [77] [78]. The prognosis of lupus nephritis depends on many demographics, racial, genetic, histopathologic, immunologic, and time-dependent factors [79]. Renal disease that fails to remit with immunosuppressive therapies is a major risk factor for subsequent deterioration of renal function and poor outcome [80] [81]. Recent studies have reiterated that lupus nephritis patients of African, Hispanic, or Asian ethnicity have generally experienced poorer outcomes [82] [83] [84] [85].

More recent studies have focused on the relative mortality of patients with lupus renal disease as compared to different reference groups [86]-[91]. However, the effect of different histologic classes of lupus glomerulonephritis on the relative mortality of SLE, as compared to mortality rates in the general population, has been largely unreported. Moreover, data on the life expectancy of patients with lupus nephritis are not available in the literature. Therefore, the present study was carried out to evaluate the effect of renal disease, histologic class of lupus nephritis, renal damage, and renal failure on the standardized mortality ratio (SMR) and life expectancy in a longitudinal cohort of SLE patients from China. The findings of the above research concluded that patients with SLE have increased mortality. This is due to multiple factors that include an increased susceptibility to infection, accelerated atherosclerosis, and malignancies, as well as organ damage due to treatment failure or complications [92]. The survival of patients with SLE has improved tremendously in the past $3-4$ decades, which is attributed to earlier diagnosis and treatment, more judicious use of corticosteroids, the emergence of novel treatments, and better supportive care for organ failure and infection-related complications [92]. However, the improvement in the SLE survival rate appears to have reached a plateau since the 1990s [93]. Patients with SLE still have a mortality rate higher than that of the general population [87] [91], although a dropping trend has been observed [94]. Renal disease is a major organ manifestation of SLE, and its presence further increases the risk of death, because the disease still progresses to ESRD in a constant proportion of patients over time [86]-[91].

\subsection{Treatment of the Diseases}

The significant diversity of lupus nephritis (LN) has been the subject of intense investigation for a long time [95]. Several attempts were made to classify the pathologic features of LN. This classification represented distinctive characteristics and hence differences in response to treatment.

Intravenous cyclophosphamide (IVCY) has been widely used as a form of therapy to induce remission of diffuse proliferative LN (also known as class IV LN) for more than 20 years [96]. Since 1997, mycophenolate mofetil (MMF) has also been used successfully for the treatment of class IV LN [97] [98] [99].

A combined therapy consisting of steroids, MMF, and tacrolimus has been applied in the field of organ transplantation for years. It was shown to be an ef- 
fective treatment for early mixed cellular and humoral renal allograft rejections [100] [101] [102] [103] [104]. Does it work in LN? Considering both the pharmacologic differences between tacrolimus and MMF and their efficacy for the treatment of renal allograft rejections, we investigated the therapeutic efficacy and adverse effects of this combined therapy (steroid + MMF + tacrolimus) in the induction treatment of class V + IV LN, in comparison with IVCY therapy.

An extensive clinical trial [95] documented important findings regarding the treatment of LN and its classes. It was noted that the overlap of class V with III $(\mathrm{Vc})$ and IV (Vd) was described as a subcategory of membranous LN in the 1982 World Health Organization classification but was eliminated in the 2003 ISN/RPS classification [105].

Although the cause of systemic lupus erythematosus remains elusive, the undeniable fact is that different types of LN may involve different immune pathogeneses. LN is characterized by the deposition of IgG4 and the absence of delayed type hypersensitivity effectors [106].

In summary, the therapeutic goal for patients with $\mathrm{LN}$ is to achieve prompt remission and avoid disease flare and chronic renal impairment. As studies have shown [107] [108] relapses of LN may be common after the induction treatment. A prolonged follow-up period is needed for the exploration of this treatment's impact on long-term prognosis and the recurrence rate during the maintenance therapy period [96].

Even with treatment, loss of kidney function sometimes progresses. If both kidneys fail, people with lupus nephritis may need dialysis. Dialysis involves filtering the blood through a machine to remove waste products from the body.

Ultimately, it may be necessary to have a kidney transplant. In those cases, people will need additional drugs to keep their immune system from rejecting the transplanted kidney.

Why is Health-Related Quality of Life \& Well-Being Important?

Healthy People 2020 emphasizes the importance of health-related quality of life and well-being by including it as one of the initiative's 4 overarching goals, "promoting quality of life, healthy development, and health behaviors across all life stages [109] [110]. It also was established as one of the HP2020 4 foundation health measures [111].

The significance of quality of life and well-being as a public health concern is not new. Since 1949, the World Health Organization (WHO) has noted that health is "a state of complete physical, mental, and social well-being and not merely an absence of disease and infirmity." [112]. In 2005, WHO recognized the importance of evaluating and improving people's quality of life in a position paper [113]. Because people are living longer than ever before, researchers have changed the way they examine health, looking beyond causes of death and morbidity to examine the relationship of health to the quality of an individual life.

When quality of life is considered in the context of health and disease, it's commonly referred to as health-related quality of life (HRQOL). Researchers today agree that HRQOL is multidimensional and includes domains that are re- 
lated to physical, mental, emotional, and social functioning and the social context in which people live [114].

HRQOL is a subjective and multidimensional concept that includes aspects of physical, mental, and social health [115] [116]. For Healthy People 2020, the Patient-Reported Outcomes Measurement Information System (PROMIS) Global Health Items were identified as reliable and valid measures of self-reported physical and mental health and are currently being considered to monitor these 2 domains across the decade. PROMIS is an NIH Roadmap initiative designed to develop an electronic system to collect self-reported HRQOL data from diverse populations of individuals with a variety of chronic diseases and demographic characteristics [117] [118].

An important study [119] on HRQOL used cross sectional data obtained from patients with systemic lupus erythematosus (SLE) during psychometric evaluation studies of Lupus from various countries were compared between those: 1) with and without LN and 2) with active and inactive-LN. Data compared included demographics, disease characteristics, and Lupus PRO constructs. Presence of LN was present if listed among the ACR classification criteria (ACR-LN), while presence of active LN was based on presence of urinary casts, hematuria, proteinuria or pyuria in the disease activity assessment (SELENA-SLEDAI) performed at the time of the study visit. Lupus PRO has Health related QOL (HRQOL) and non-HRQOL constructs. HRQOL domains include lupus symptoms, cognition, medication, procreation, physical health, emotional health, pain-vitality, and body image. Non-HRQOL domains include desires-goals, social support, coping and satisfaction with care. Non-parametric tests were used to make comparisons, and $\mathrm{p}$ values $\leq 0.05$ were considered significant.

The results of the study are summarized here. There were 1259 SLE patients. Five-hundred and thirty-nine had ACR-LN. These patients were younger, had greater disease activity (PGA, Total SELENA-SLEDAI) and damage (SLICC/ACR) than those without LN. Summary HRQOL and non-HRQOL scores were similar in both groups; however, those with ACR-LN had significantly worse scores on medications and procreation domains, while those without ACR-LN had worse scores on Pain-Vitality domains.

129/540 ACR-LN patients had active LN. Patients with active LN were younger, had significantly greater disease activity (PGA, Total SELENA-SLEDAI), worse HRQOL and non-HRQOL than patients with inactive LN. Specific domains scores adversely affected among active LN patients were lupus symptoms, medications, procreation, emotional health, body image and desires-goals. Satisfaction with care was significantly higher among patients with active LN as compared to inactive LN patients. We conducted meta-analytic approach using components of the study (study factors) [119]. In Figure 1: study = components of the HRQOL, Experimental $=$ LN_NO, and Control $=$ LN_YES.

In Figure 2, study $=$ components of the HRQOL, Experimental = ACR_LN $(\mathrm{NO})$, control = ACR_LN (YES). These notations are the default naming of groups provided by the software program $\mathrm{R}$. 


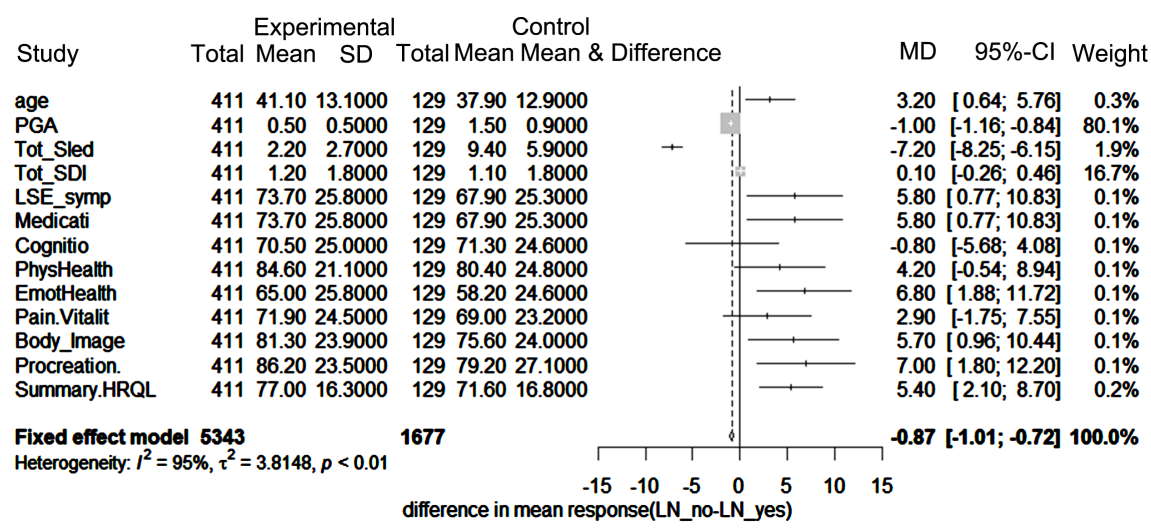

Figure 1. Confidence levels for LN_ACTIVE (NO) as compared to the LN_ACTIVE (YES).

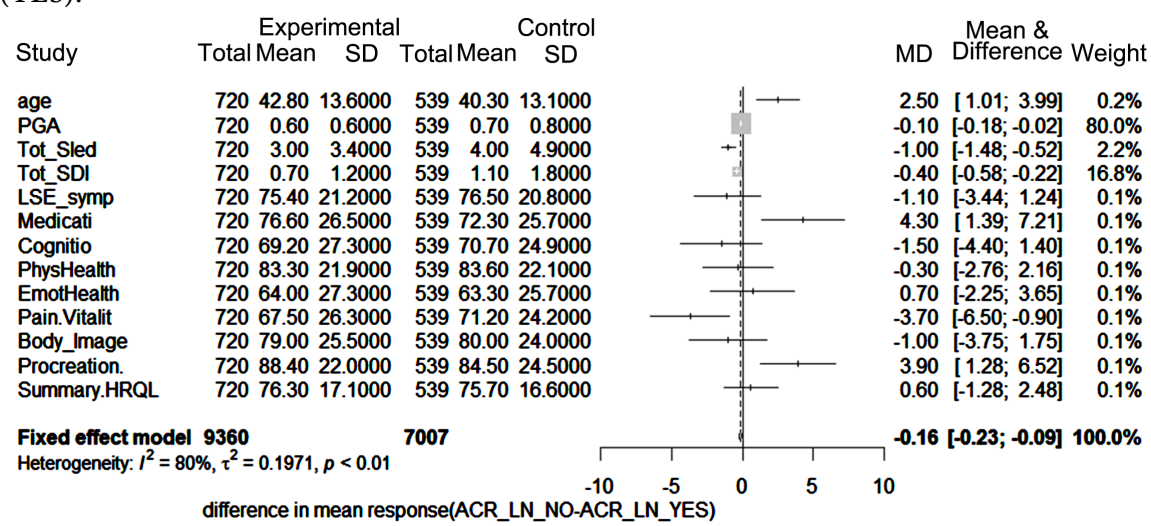

Figure 2. Confidence levels for ACR_LN (NO) as compared to the ACR_LN (YES).

The Pearson's correlation among the HRQOL scores between ACR_LN (NO) and ACR_LN (YES) is 0.998.

The Pearson's correlation among the HRQOL scores between LN_ACTIVE (NO) and LN_ACTIVE (YES) is 0.997.

Several important components of the HRQOL instruments need explanation in the above figures; they are "The Physician Global Assessment" (PGA). The PGA [120] is a visual analogue score that reflects the clinician's judgment of overall SLE disease activity.

Construct validity was demonstrated by a good correlation $(r \geq 0.50)$ between the PGA with the SLEDAI [121]. The SLEDAI is a global index that was developed and introduced in 1985 as a clinical index for the assessment of lupus disease activity in the preceding 10 days. It consists of 24 weighted clinical and laboratory variables of nine organ systems. This instrument was derived by consensus among experts in rheumatology followed by application of regression models to assign relative weights to each parameter. SLEDAI was modeled based on clinician global judgment.

A modified version of the SLEDAI (SELENA-SLEDAI) was devised for use in the Safety of Estrogens in Lupus National Assessment (SELENA) study. A glossary was added, and the scoring was modified to account for persistent active disease in some descriptors (rash, mucosal ulcers, and alopecia), which were pre- 
viously not scored unless they were new or recurrent.

In the SELENA-SLEDAI, researchers accepted the presence of either objective or subjective findings to score the descriptor as present [19]. The SELENASLEDAI version awaits rigorous validation with other measures related to disease activity in SLE.SLEDAI-2000 SLEDAI-2000 (SLEDAI-2 K) was introduced in 2002 as a measure of global disease activity. SLEDAI-2 $\mathrm{K}$ is a modification of the original SLEDAI to allow the documentation of persistent.

\section{Discussion}

The fundamental goals of treatment of patients with SLE are to improve long-term patient outcomes. Management should aim at remission of disease symptoms and signs, prevention of damage accrual and minimization of drug side-effects, as well as improvement of quality of life [122] [123]. Complete remission (absence of clinical activity with no use of GC and IS drugs) is infrequent [124] [125] [126] [127] [128]. To this end, newly defined low disease activity states (based on a SLEDAI score $\leq 3$ on antimalarials, or alternatively SLEDAI $\leq 4, \mathrm{PGA} \leq 1$ with $\mathrm{GC} \leq 7.5$ $\mathrm{mg}$ of prednisone and well-tolerated IS agents) have shown comparable rates with remission, regarding halting of damage accrual [129] [130] [131] [132]. Accordingly, treatment in SLE should aim at remission or, if this state cannot be achieved, at low disease activity in all organ systems.

Prevention of disease flares is an additional milestone of SLE treatment. Although a universally accepted definition is lacking, most experts agree that a flare is a measurable increase in disease activity usually leading to change of treatment [133] [134] [135].

Another issue related to the human burden of the disease is "Risk of infection" associated with both disease-related and treatment-related factors; high-dose GC therapy, CYC, MMF and RTX are all associated with an increased risk for infection, while high disease activity, severe leucopenia and presence of renal involvement in nephrotic syndrome also contribute independently. Protection against infections should be proactive, focusing both on primary prevention, as well as timely recognition and treatment. Patients with lupus should receive vaccinations according to the EULAR [136] recommendations for vaccination of patients with autoimmune rheumatic diseases [137] [138]. Immunization against seasonal influenza and pneumococcal infection (both PCV13 and PPSV23) should be strongly considered, preferably during stable disease.

SLE is an independent risk factor for cardiovascular disease (CVD), due to both traditional and disease-related risk factors, such as persistent disease activity, LN, presence of aPL and use of GC [139] [140] [141]. Low-dose aspirin may be considered for primary prevention of CVD, as it may reduce the risk for incident CVD in SLE [142].

However, this must be viewed considering recent large studies in diabetics and elderly showing that the benefits of aspirin for primary CVD prevention are counterbalanced by the larger bleeding hazard [143] [144]. 
As a final statement, there is no cure for LN. The reference [145] provides a recent update to the recommended treatment of LN. The main objectives of the treatment are to reduce symptoms or make symptoms disappear (remission), keep the disease from getting worse, maintain remission, and avoid the need for kidney transplant. For severe LN, [145] recommends, to stop the immune system from attacking healthy cells, several treatment options such as: Cyclosporine, Tacrolimus, Cyclophosphamide Azathioprine (Imuran), Mycophenolate, and Rituximab (Rituxan).

In addition to the human suffering attributed to the disease, there is the economic impact and the cost of disease management. These issues warrant research within the framework of the field of "Health Economics".

\section{Acknowledgements}

The author would like to acknowledge the constructive comments for an anonymous reviewer.

\section{Conflicts of Interest}

The author declares no conflicts of interest regarding the publication of this paper.

\section{References}

[1] Smith, C.D. and Cyr, M. (1988) The History of Lupus Erythematosus, from Hippocrates to Osler. Rheumatic Disease Clinics of North America, 14, 1-14. https://doi.org/10.1016/S0889-857X(21)00942-X

[2] Cazenave, P.L.A. and Schedel, H.E. (1852) Manual of the Diseases of the Skin. Burgess, Trans., Henry Renshaw, London.

[3] Hebra, F. (1866) On Diseases of the Skin Including the Exanthemata. Vol. 1. Adams, F., Trans., The New Sydenham Society, London.

[4] Kaposi, M. (1875) Lupus vulgaris. In: Hebra, F. and Kaposi, M., Eds., On Diseases of the Skin Including the Exanthemata, Vol. IV. Tay, W., Trans., The New Sydenham Society, London.

[5] Osler, W. (1895) On the Visceral Complications of Erythema Exudativum Multiforme. The American Journal of the Medical Sciences, 110, 629-646.

[6] Jadassohn, J. (1904) Lupus Erythematodes. In: Mracek, F., Eds., Handbuch der Hautkrankheiten, Alfred Holder, Wein, 298-404.

[7] Klemperer, P., Pollack, A. and Baehr, G. (1984) Diffuse Collagen Disease: Acute Disseminated Lupus Erythematosus and Diffuse Scleroderma. JAMA, 251, 1593-1594. https://doi.org/10.1001/jama.1984.03340360059032

[8] Hargraves, M.M. (1969) Discovery of the LE Cell and Its Morphology. Mayo Clinic Proceedings, 44, 579-599.

[9] Moore, J.E. and Lutz, W.B. (1955) The Natural History of Systemic Lupus Erythematosus: An Approach to Its Study through Chronic Biological False Positive Reactions. Journal of Chronic Diseases, 2, 297-316. https://doi.org/10.1016/0021-9681(55)90039-4

[10] Bielschowsky, M., Helyer, B.J. and Howie, J.B. (1959) Spontaneous Hemolytic 
Anemia in Mice of the NZB/BL Strain. Proceedings of the University of Otago Medical School, 37, Article No. 9.

[11] Longo, D.L., Kasper, D.L., Larry, J.J., Fauci, A.S. and Hauser, S.L. (2011) Harrison's Principles of Internal Medicine. 18th Edition, McGraw-Hill Professional Pub, New York.

[12] Cojocaru, M., Cojocaru, I.M., Silosi, I. And Vrabie, C.D. (2011) Manifestations of Systemic Lupus Erythematosus. Maedica: A Journal of Clinical Medicine, 6, 330-336.

[13] Lee, Y.H., Woo, J.H., Choi, S.J., Ji, J.D. and Song, G.G. (2010) Induction and Maintenance Therapy for Lupus Nephritis: A Systematic Review and Meta-Analysis. Lupus, 19, 703-710. https://doi.org/10.1177\%2F0961203309357763

[14] Edwards, C.J., Lian, T.Y., Badsha, H., The, C.L., Arden, N. and Chng, H.H. (2003) Hospitalization of Individuals with Systemic Lupus Erythematosus: Characteristics and Predictors of Outcome. Lupus, 12, 672-676.

[15] Ugarte-Gil, M.F., Acevedo-Vásquez, E., Alarcón, G.S., Pastor-Asurza, C.A., Alfaro-Lozano, J.L., Cucho-Venegas, J.M., et al., on behalf of GLADEL (2015) The Number of Flares Patients Experience Impacts on Damage Accrual in Systemic Lupus Erythematosus: Data from a Multiethnic Latin American Cohort. Annals of the Rheumatic Diseases, 74, 1019-1023. https://doi.org/10.1136/annrheumdis-2013-204620

[16] Bruce, I.N., O’Keeffe, A.G., Farewell, V., Hanly, J.G., Manzi, S., Su, L., et al. (2015) Factors Associated with Damage Accrual in Patients with Systemic Lupus Erythematosus: Results from the Systemic Lupus International Collaborating Clinics (SLICC) Inception Cohort. Annals of the Rheumatic Diseases, 74, 1706-1713.

https://doi.org/10.1136/annrheumdis-2013-205171

[17] Yee, C.S., Su, L., Toescu, V., Hickman, R., Situnayake, D., Bowman, S., et al. (2015) Birmingham SLE Cohort: Outcomes of a Large Inception Cohort Followed for Up to 21 Years. Rheumatology, 54, 836-843. https://doi.org/10.1093/rheumatology/keu412

[18] Al Sawah, S., Zhang, X., Zhu, B., Magder, L.S., Foster, S.A., Iikuni, N., et al. (2015) Effect of Corticosteroid Use by Dose on the Risk of Developing Organ Damage over Time in Systemic Lupus Erythematosus-The Hopkins Lupus Cohort. Lupus Science \& Medicine, 2, Article ID: e000066. https://doi.org/10.1136/lupus-2014-000066

[19] Pryor, W.A. and Stone, K. (1993) Oxidants in Cigarette Smoke. Radicals, Hydrogen Peroxide, Peroxynitrate, and Peroxynitrite. Annals of the New York Academy of Sciences, 686, 12-27. https://doi.org/10.1111/j.1749-6632.1993.tb39148.x

[20] Bijl, M., Horst, G., Limburg, P. and Kallenberg, C. (2001) Effects of Smoking on Activation Markers, Fas Expression and Apoptosis of Peripheral Blood Lymphocytes. European Journal of Clinical Investigation, 31, 550-553. https://doi.org/10.1046/j.1365-2362.2001.00842.x

[21] Freemer, M.M., King Jr., T.E. and Criswell, L.A. (2006) Association of Smoking with dsDNA Autoantibody Production in Systemic Lupus Erythematosus. Annals of the Rheumatic Diseases, 65, 581-584. https://doi.org/10.1136/ard.2005.039438

[22] Kiyohara, C., Washio, M., Horiuchi, T., Asami, T., Ide, S., Atsumi, T., et al. (2012) Cigarette Smoking, Alcohol Consumption, and Risk of Systemic Lupus Erythematosus: A Case-Control Study in a Japanese Population. The Journal of Rheumatology, 39, 1363-1370. https://doi.org/10.3899/jrheum.111609

[23] Washio, M., Horiuchi, T., Kiyohara, C., Kodama, H., Tada, Y., Asami, T., et al. (2006) Smoking, Drinking, Sleeping Habits, and Other Lifestyle Factors and the Risk of Systemic Lupus Erythematosus in Japanese Females: Findings from the 
KYSS Study. Modern Rheumatology, 16, 143-150. https://doi.org/10.3109/s10165-006-0474-6

[24] Kuhn, A. and Beissert, S. (2005) Photosensitivity in Lupus Erythematosus. Autoimmunity, 38, 519-529. https://doi.org/10.1080/08916930500285626

[25] Cantorna, M.T. and Mahon, B.D. (2004) Mounting Evidence for Vitamin D as an Environmental Factor Affecting Autoimmune Disease Prevalence. Experimental Biology and Medicine, 229, 1136-1142. https://doi.org/10.1177\%2F153537020422901108

[26] McClain, M.T., Poole, B.D., Bruner, B.F., Kaufman, K.M., Harley, J.B. and James, J.A. (2006) An Altered Immune Response to Epstein-Barr Nuclear Antigen 1 in Pediatric Systemic Lupus Erythematosus. Arthritis \& Rheumatism, 54, 360-368. https://doi.org/10.1002/art.21682

[27] Ulff-Moller, C.J., Nielsen, N.M. and Rostgaard, K. (2010) Epstein-Barr Virus-Associated Infectious Mononucleosis and Risk of Systemic Lupus Erythematosus. Rheumatology, 49, 1706-1712. https://doi.org/10.1093/rheumatology/keq148

[28] Cooper, G.S., Dooley, M.A., Treadwell, E.L. and William St Clair, E. (2002) Risk Factors for Development of Systemic Lupus Erythematosus: Allergies, Infections, and Family History. Journal of Clinical Epidemiology, 55, 982-989. https://doi.org/10.1016/S0895-4356(02)00429-8

[29] Blanc, P.D., Jarvholm, B. and Toren, K. (2015) Prospective Risk of Rheumatologic Disease Associated with Occupational Exposure in a Cohort of Male Construction Workers. American Journal of Medicine, 128, 1094-1101.

https://doi.org/10.1016/j.amjmed.2015.05.001

[30] Pereira, F.A., de Assuncao, J.V., Saldiva, P.H., Pereira, L.A., Mirra, A.P. and Braga, A.L. (2005) Influence of Air Pollution on the Incidence of Respiratory Tract Neoplasm. Journal of the Air \& Waste Management Association, 55, 83-87. https://doi.org/10.1080/10473289.2005.10464603

[31] Gilbert, K.M., Rowley, B., Gomez-Acevedo, H. and Blossom, S.J. (2011) Coexposure to Mercury Increases Immunotoxicity of Trichloroethylene. Toxicological Sciences, 119, 281-292. https://doi.org/10.1093/toxsci/kfq345

[32] Gardner, R.M., Nyland, J.F., Silva, I.A., Ventura, A.M., de Souza, J.M. and Silbergeld, E.K. (2010) Mercury Exposure, Serum Antinuclear/Antinucleolar Antibodies, and Serum Cytokine Levels in Mining Populations in Amazonian Brazil: A CrossSectional Study. Environmental Research, 110, 345-354.

https://doi.org/10.1016/j.envres.2010.02.001

[33] Li, Y., Gorelik, G., Strickland, F.M. and Richardson, B.C. (2014) Oxidative Stress, T Cell DNA Methylation, and Lupus. Arthritis \& Rheumatology, 66, 1574-1582. https://doi.org/10.1002/art.38427

[34] Somers, E.C. and Richardson, B.C. (2014) Environmental Exposures, Epigenetic Changes and the Risk of Lupus. Lupus, 23, 568-576.

https://doi.org/10.1177\%2F0961203313499419

[35] Strickland, F.M., Hewagama, A., Wu, A., Sawalha, A.H., Delaney, C., Hoeltzel, M.F., et al. (2013) Diet Influences Expression of Autoimmune-Associated Genes and Disease Severity by Epigenetic Mechanisms in a Transgenic Mouse Model of Lupus. Arthritis \& Rheumatism, 65, 1872-1881. https://doi.org/10.1002/art.37967

[36] Sofi, F., Cesari, F., Abbate, R., Gensini, G.F. and Casini, A. (2008) Adherence to Mediterranean Diet and Health Status: Meta-Analysis. BMJ, 337, Article No. a1344. https://doi.org/10.1136/bmj.a1344

[37] Zampelas, A., Panagiotakos, D., Pitsavos, C., Chrysohoou, C. And Stefanadis, C. 
(2004) Associations between Coffee Consumption and Inflammatory Markers in Healthy Persons: The ATTICA Study. American Journal of Clinical Nutrition, 80, 862-867. https://doi.org/10.1093/ajcn/80.4.862

[38] Kiyohara, C., Washio, M., Horiuchi, T., Asami, T., Ide, S., Atsumi, T., et al. (2014) Modifying effect of $\mathrm{N}$-Acetyltransferase 2 Genotype on the Association between Systemic Lupus Erythematosus and Consumption of Alcohol and Caffeine-Rich Beverages. Arthritis Care \& Research, 66, 1048-1056. https://doi.org/10.1002/acr.22282

[39] Moser, K.L., Kelly, J.A., Lessard, C.J. and Harley, J.B. (2009) Recent Insights into the genetic Basis of Systemic Lupus Erythematosus. Genes and Immunity, 10, 373-379. https://doi.org/10.1038/gene.2009.39

[40] Barrett, J.C., Hansoul, S., Nicolae, D.L., Cho, J.H., Duerr, R.H., Rioux, J.D., et al. (2008) Genome-Wide Association Defines More than 30 Distinct Susceptibility Loci for Crohn's Disease. Nature Genetics, 40, 955-962. https://doi.org/10.1038/ng.175

[41] Harley, J.B., Alarcon-Riquelme, M.E., Criswell, L.A., Jacob, C.O., Kimberly, R.P., Moser, K.L., et al. (2008) Genome-Wide Association Scan in Women with Systemic Lupus Erythematosus Identifies Susceptibility Variants in ITGAM, PXK, KIAA1542 and Other Loci. Nature Genetics, 40, 204-210. https://doi.org/10.1038/ng.81

[42] Lu, X., Chen, X., Forney, C., Donmez, O., Miller, D., Parameswaran, S., Hong, T., Huang, Y., Pujato, M., Cazares, T., Miraldi, E.R., Ray, J.P., de Boer, C.G., Harley, J.B., Weirauch, M.T. and Kottyan, L.C. (2021) Global Discovery of Lupus Genetic Risk Variant Allelic Enhancer Activity. Nature Communications, 12, Article No. 1611. https://doi.org/10.1038/s41467-021-21854-5

[43] Kuo, C.-F., Grainge, M.J., Valdes, A.M., See, L.-C., Luo, S.-F., Yu, K.-H., et al. (2015) Familial Aggregation of Systemic Lupus Erythematosus and Coaggregation of Autoimmune Diseases in Affected Families. JAMA Internal Medicine, 175, 1518 1526. https://doi.org/10.1001/jamainternmed.2015.3528

[44] Priori, R., Medda, E., Conti, F., et al. (2003) Familial Autoimmunity as a Risk Factor for Systemic Lupus Erythematosus and Vice Versa: A Case-Control Study. Lupus, 12, 735-740. https://doi.org/10.1191/0961203303lu457oa

[45] Iwamoto, T. and Niewold, T.B. (2017) Genetics of Human Lupus Nephritis. Clinical Immunology, 185, 32-39. https://doi.org/10.1016/j.clim.2016.09.012

[46] Tsokos, G.C. (2011) Systemic Lupus Erythematosus. The New England Journal of Medicine, 365, 2110-2121. https://doi.org/10.1056/NEJMra1100359

[47] Sanchez, E., Rasmussen, A., Riba, L., Acevedo-Vasquez, E., Kelly, J.A., Langefeld, C.D., et al. (2012) Impact of Genetic Ancestry and Sociodemographic Status on the Clinical Expression of Systemic Lupus Erythematosus in American Indian-European Populations. Arthritis and Rheumatism, 64, 3687-3694.

https://doi.org/10.1002/art.34650

[48] Borchers, A.T., Leibushor, N., Naguwa, S.M., Cheema, G.S., Shoenfeld, Y. and Gershwin, M.E. (2012) Lupus Nephritis: A Critical Review. Autoimmunity Reviews, 12, 174-194. https://doi.org/10.1016/j.autrev.2012.08.018

[49] Borchers, A.T., Naguwa, S.M., Shoenfeld, Y. and Gershwin, M.E. (2010) The Geoepidemiology of Systemic Lupus Erythematosus. Autoimmunity Reviews, 9, A277-A287. https://doi.org/10.1016/j.autrev.2009.12.008

[50] Deapen, D., Escalante, A., Weinrib, L., Horwitz, D., Bachman, B., Roy-Burman, P., Walker, A. and Mack, T.M. (1992) A Revised Estimate of Twin Concordance in Systemic Lupus Erythematosus. Arthritis \& Rheumatism, 35, 311-318. https://doi.org/10.1002/art.1780350310 
[51] Alarcon-Segovia, D., Alarcon-Riquelme, M.E., Cardiel, M.H., Caeiro, F., Massardo, L., Villa, A.R. and Pons-Estel, B.A. (2005) Familial Aggregation of Systemic Lupus Erythematosus, Rheumatoid Arthritis, and Other Autoimmune Diseases in 1,177 Lupus Patients from the GLADEL Cohort. Arthritis \& Rheumatism, 52, 1138-1147. https://doi.org/10.1002/art.20999

[52] Harper, L., et al. (2007) FCGR3B Copy Number Variation Is Associated with Susceptibility to Systemic but Not Organ Specific, Auto-Immunity. Nature Genetic, 39, 721-723. https://doi.org/10.1038/ng2046

[53] Hom, G., Graham, R.R., Modrek, B., Taylor, K.E., Ortmann, W., et al. (2008) Association of Systemic Lupus Erythematosus with C8orf13-BLK and ITGAM-ITGAX. The New England Journal of Medicine, 358, 900-909. https://doi.org/10.1056/NEJMoa0707865

[54] Chung, S.A., Brown, E.E., Williams, A.H., Ramos, P.S., Berthier, C.C., Bhangale, T., et al. (2014) Lupus Nephritis Susceptibility Loci in Women with Systemic Lupus Erythematosus. Journal of the American Society of Nephrology, 25, 2859-2870. https://doi.org/10.1681/ASN.2013050446

[55] Freedman, B.I., Langefeld, C.D., Andringa, K.K., Croker, J.A., Williams, A.H., Garner, N.E., et al. (2014) End-Stage Renal Disease in African Americans with Lupus Nephritis Is Associated with APOL1. Arthritis \& Rheumatology, 66, 390-396. https://doi.org/10.1002/art.38220

[56] Hanly, J.G., O’Keeffe, A.G., Su, L., Urowitz, M.B., Romero-Diaz, J., Gordon, C., et al. (2016) The Frequency and Outcome of Lupus Nephritis: Results from an International Inception Cohort Study. Rheumatology, 55, 252-262. https://doi.org/10.1093/rheumatology/kev311

[57] Costenbader, K.H., Desai, A., Alarcon, G.S., Hiraki, L.T., Shaykevich, T., Brookhart, M.A., et al. (2011) Trends in the Incidence, Demographics, and Outcomes of End-Stage Renal Disease Due to Lupus Nephritis in the US from 1995 to 2006. Arthritis and Rheumatism, 63, 1681-1688. https://doi.org/10.1002/art.30293

[58] Croca, S.C., Rodrigues, T. and Isenberg, D.A. (2011) Assessment of a Lupus Nephritis Cohort over a 30-Year Period. Rheumatology, 50, 1424-1430.

https://doi.org/10.1093/rheumatology/ker101

[59] Calvo-Alen, J., Reveille, J.D., Rodriguez-Valverde, V., McGwin Jr., G., Baethge, B.A., Friedman, A.W. and Alarcon, G.S. (2003) Clinical, Immunogenetic and Outcome Features of Hispanic Systemic Lupus Erythematosus Patients of Different Ethnic Ancestry. Lupus, 12, 377-385. https://doi.org/10.1191\%2F0961203303lu372oa

[60] Seligman, V.A., Lum, R.F., Olson, J.L., Li, H. and Criswell, L.A. (2002) Demographic Differences in the Development of Lupus Nephritis: A Retrospective Analysis. The American Journal of Medicine, 112, 726-729. https://doi.org/10.1016/S0002-9343(02)01118-X

[61] Alarcon, G.S., McGwin Jr., G., Petri, M., Reveille, J.D., Ramsey-Goldman, R. and Kimberly, R.P. (2002) Baseline Characteristics of a Multiethnic Lupus Cohort: PROFILE. Lupus, 11, 95-101.

[62] Barr, R.G., Seliger, S., Appel, G.B., Zunig,a R., D’Agati, V., Salmon, J. and Radhakrishnan, J. (2003) Prognosis in Proliferative Lupus Nephritis: The Role of Socio-Economic Status and Race/Ethnicity. Nephrology Dialysis Transplantation, 18, 2039-2046. https://doi.org/10.1093/ndt/gfg345

[63] Freedman, B.I., Wilson, C.H., Spray, B.J., Tuttle, A.B., Olorenshaw, I.M. and Kammer, G.M. (1997) Familial Clustering of End-Stage Renal disease in Blacks with 
Lupus Nephritis. American Journal of Kidney Diseases, 29, 729-732. https://doi.org/10.1016/S0272-6386(97)90126-8

[64] Goldberg, M.A., Arnett, F.C., Bias, W.B. and Shulman, L.E. (1976) Histocompatibility Antigens in Systemic Lupus Erythematosus. Arthritis \& Rheumatism, 19, 129-132. https://doi.org/10.1002/art.1780190201

[65] Zhang, Y., Zhao, M., Sawalha, A.H., Richardson, B. and Lu, Q. (2013) Impaired DNA Methylation and Its Mechanisms in CD4 ${ }^{+} \mathrm{T}$ Cells of Systemic Lupus Erythematosus. Journal of Autoimmunity, 41, 92-99. https://doi.org/10.1016/j.jaut.2013.01.005

[66] Richardson, B., Scheinbart, L., Strahler, J., Gross, L., Hanash, S. and Johnson, M. (1990) Evidence for Impaired T Cell DNA Methylation in Systemic Lupus Erythematosus and Rheumatoid Arthritis. Arthritis \& Rheumatism, 33, 1665-1673. https://doi.org/10.1002/art.1780331109

[67] Zhao, M., Liu, S., Luo, S., Wu, H., Tang, M., Cheng, W., et al. (2014) DNA Methylation and mRNA and microRNA Expression of SLE CD4+ T Cells Correlate with Disease Phenotype. Journal of Autoimmunity, 54, 127-136.

https://doi.org/10.1016/j.jaut.2014.07.002

[68] Renauer, P., Coit, P., Jeffries, M.A., Merrill, J.T. and McCune, W.J. (2015) Maksimowicz-McKinnon K, Sawalha AH. DNA Methylation Patterns in Naive CD4+ T Cells Identify Epigenetic Susceptibility Loci for Malar Rash and Discoid Rash in Systemic Lupus Erythematosus. Lupus Science \& Medicine, 2, Article No. e000101. https://doi.org/10.1136/lupus-2015-000101

[69] Absher, D.M., Li, X., Waite, L.L., Gibson, A., Roberts, K., Edberg, J., Chatham, W.W. and Kimberly, R.P. (2013) Genome-Wide DNA Methylation Analysis of Systemic Lupus Erythematosus Reveals Persistent Hypomethylation of Interferon Genes and Compositional Changes to CD4+ T-Cell Populations. PLoS Genetics, 9, e1003678. https://doi.org/10.1371/journal.pgen.1003678

[70] Coit, P., Jeffries, M., Altorok, N., Dozmorov, M.G., Koelsch, K.A., Wren, J.D., Merrill, J.T., McCune, W.J. and Sawalha, A.H. (2013) Genome-Wide DNA Methylation Study Suggests Epigenetic Accessibility and Transcriptional Poising of Interferon-Regulated Genes in Naive CD4+ T Cells from Lupus Patients. Journal of Autoimmunity, 43, 78-84. https://doi.org/10.1016/j.jaut.2013.04.003

[71] Coit, P., Renauer, P., Jeffries, M.A., Merrill, J.T., McCune, W.J., Maksimowicz-McKinnon, K. and Sawalha, A.H. (2015) Renal Involvement in Lupus Is Characterized by Unique DNA Methylation Changes in Naive CD4+ T Cells. Journal of Autoimmunity, 61, 29-35. https://doi.org/10.1016/j.jaut.2015.05.003

[72] Mok, C.C., Kwok, R.C.L. and Yip, P.S.F. (2013) Effect of Renal Disease on the Standardized Mortality Ratio and Life Expectancy of Patients with Systemic Lupus Erythematosus. Arthritis \& Rheumatism, 65, 2154-2160. https://doi.org/10.1002/art.38006

[73] Mok, C.C., Wong, W.S. and Lau, C.S. (1999) Lupus Nephritis in Southern Chinese Patients: Clinicopathologic Findings and Long-Term Outcome. American Journal of Kidney Diseases, 34, 315-323. https://doi.org/10.1016/S0272-6386(99)70361-6

[74] Donadio Jr., J.V., Hart, G.M., Bergstralh, E.J. and Holley, K.E. (1995) Prognostic Determinants in Lupus Nephritis: A Long-Term Clinicopathologic Study. Lupus, 4, 109-115. https://doi.org/10.1177\%2F096120339500400206

[75] Bono, L., Cameron, J.S. and Hicks, J.A. (1999) The Very Long-Term Prognosis and Complications of Lupus Nephritis and Its Treatment. QJM: An International Journal of Medicine, 92, 211-218. https://doi.org/10.1093/qjmed/92.4.211 
[76] Neumann, K., Wallace, D.J., Azen, C., Nessim, S., Fichman, M., Metzger, A.L., et al. (1995) Lupus in the 1980s: III. Influence of Clinical Variables, Biopsy, and Treatment on the Outcome in 150 Patients with Lupus Nephritis Seen at a Single Center. Seminars in Arthritis and Rheumatism, 25, 47-55. https://doi.org/10.1016/S0049-0172(95)80017-4

[77] Bakir, A.A., Levy, P.S. and Dunea, G. (1994) The Prognosis of Lupus Nephritis in African-Americans: A Retrospective Analysis. American Journal of Kidney Diseases, 24, 159-171. https://doi.org/10.1016/S0272-6386(12)80177-6

[78] Nossent, H.C. and Koldingsnes, W. (2000) Long-Term Efficacy of Azathioprine Treatment for Proliferative Lupus Nephritis. Rheumatology, 39, 969-974.

https://doi.org/10.1093/rheumatology/39.9.969

[79] Mok, C.C. (2005) Prognostic Factors in Lupus Nephritis. Lupus, 14, 39-44. https://doi.org/10.1191\%2F0961203305lu2057oa

[80] Korbet, S.M., Lewis, E.J., Schwartz, M.M., Reichlin, M., Evans, J. and Rohde, R.D. (2000) Lupus Nephritis Collaborative Study Group. Factors Predictive of Outcome in Severe Lupus Nephritis. American Journal of Kidney Diseases, 35, 904-914. https://doi.org/10.1016/S0272-6386(00)70262-9

[81] Mok, C.C., Ying, K.Y., Ng, W.L., Lee, K.W., To, C.H., Lau, C.S., et al. (2006) Long-Term Outcome of Diffuse Proliferative Lupus Glomerulonephritis Treated with Cyclophosphamide. American Journal of Medicine, 119, 355.e25-355.e33. https://doi.org/10.1016/j.amjmed.2005.08.045

[82] Ong, C., Nicholls, K. and Becker, G. (2011) Ethnicity and Lupus Nephritis: An Australian Single Center Study. Internal Medicine Journal, 41, 270-278. https://doi.org/10.1111/j.1445-5994.2009.02159.x

[83] Korbet, S.M., Schwartz, M.M., Evans, J. and Lewis E.J., for the Collaborative Study Group (2007) Severe Lupus Nephritis: Racial Differences in Presentation and Outcome. Journal of the American Society of Nephrology, 18, 244-254. https://doi.org/10.1681/ASN.2006090992

[84] Fernandez, M., Alarcon, G.S., Calvo-Alen, J., Andrade, R., McGwin, Jr., G, Vila, L.M., et al., for the LUMINA Study Group (2007) A Multiethnic, Multicenter Cohort of Patients with Systemic Lupus Erythematosus (SLE) as a Model for the Study of Ethnic Disparities in SLE. Arthritis Care \& Research, 57, 576-584. https://doi.org/10.1002/art.22672

[85] Hiraki, L.T., Lu, B., Alexander, S.R., Shaykevich, T., Alarcon, G.S., Solomon, D.H., et al. (2011) End-Stage Renal Disease Due to Lupus Nephritis among Children in the US, 1995-2006. Arthritis \& Rheumatism, 63, 1988-1997. https://doi.org/10.1002/art.30350

[86] Ward, M.M. (2000) Cardiovascular and Cerebrovascular Morbidity and Mortality among Women with End-Stage Renal Disease Attributable to Lupus Nephritis. American Journal of Kidney Diseases, 36, 516-525. https://doi.org/10.1053/ajkd.2000.9792

[87] Bernatsky, S., Boivin, J.F., Joseph, L., Manzi, S., Ginzler, E., Gladman, D.D., et al. (2006) Mortality in Systemic Lupus Erythematosus. Arthritis \& Rheumatism, 54, 2550-2557. https://doi.org/10.1002/art.21955

[88] Danila, M.I., Pons-Estel, G.J., Zhang, J., Vila, L.M., Reveille, J.D. and Alarcon, G.S. (2009) Renal Damage Is the Most Important Predictor of Mortality within the Damage Index: Data from LUMINA LXIV, a Multiethnic US Cohort. Rheumatolo$g y$, 48, 542-545. https://doi.org/10.1093/rheumatology/kep012

[89] Al Arfaj, A.S., Khalil, N. and Al Saleh, S. (2009) Lupus Nephritis among 624 Cases 
of Systemic Lupus Erythematosus in Riyadh, Saudi Arabia. Rheumatology International, 29, 1057-1067. https://doi.org/10.1007/s00296-009-0905-8

[90] Faurschou, M., Dreyer, L., Kamper, A.L., Starklint, H. and Jacobsen, S. (2010) Long-Term Mortality and Renal Outcome in a Cohort of 100 Patients with Lupus Nephritis. Arthritis Care \& Research, 62, 873-880. https://doi.org/10.1002/acr.20116

[91] Hersh, A.O., Trupin, L., Yazdany, J., Panopalis, P., Julian, L., Katz, P., et al. (2010) Childhood-Onset Disease as a Predictor of Mortality in an Adult Cohort of Patients with Systemic Lupus Erythematosus. Arthritis Care \& Research, 62, 1152-1159. https://doi.org/10.1002/acr.20179

[92] Mok, C.C. (2011) Epidemiology and Survival of Systemic Lupus Erythematosus in Hong Kong Chinese. Lupus, 20, 767-771. https://doi.org/10.1177\%2F0961203310388447

[93] Petri, M. (2002) Epidemiology of Systemic Lupus Erythematosus. Best Practice \& Research Clinical Rheumatology, 16, 847-858. https://doi.org/10.1053/berh.2002.0259

[94] Mok, C.C., To, C.H., Ho, L.Y. and Yu, K.L. (2008) Incidence and Mortality of Systemic Lupus Erythematosus in a Southern Chinese Population, 2000-2006. The Journal of Rheumatology, 35, 1978-1982.

[95] Bao, H., Liu, Z.-H., Xie, H.-L., Hu, W.-X., Zhang, H.-T. and Li, L.-S. (2008) Successful Treatment of Class V+IV Lupus Nephritis with Multitarget Therapy. American Society of Nephrology, 19, 2001-2010. https://doi.org/10.1681/ASN.2007121272

[96] Karim, Y. and D'Cruz, D.P. (2004) The NIH Pulse Cyclophosphamide Regime: The End of an Era? Lupus, 13, 1-3. https://doi.org/10.1191\%2F0961203304lu524ed

[97] Li, L.S., Liu, Z.H., Zhou, H. and Hu, W.X. (1998) Mycophenolate Mofetil Showed Inhibitory Effect on VACM Expression during Successful Treatment of Diffuse Proliferative Lupus Nephritis (SLE-DPGN) with Vascular Lesions. In: ASN Program and Abstracts, Williams \& Wilkins, Philadelphia, 153.

[98] Hu, W., Liu, Z., Chen, H., Tang, Z., Wang, Q., Shen, K. and Li, L. (2002) Mycophenolate Mofetil vs Cyclophosphamide Therapy for Patients with Diffuse Proliferative Lupus Nephritis. Chinese Medical Journal, 115, 705-709.

[99] Chan, T.M., Li, F.K., Tang, C.S., Wong, R.W., Fang, G.X., Ji, Y.L., Lau, C.S., Wong, A.K., Tong, M.K., Chan, K.W. and Lai, K.N., for the Hong Kong-Guangzhou Nephrology Study Group (2000) Efficacy of Mycophenolate Mofetil in Patients with Diffuse Proliferative Lupus Nephritis. New England Journal of Medicine, 343, 1156-1162. https://doi.org/10.1056/NEJM200010193431604

[100] Najafi, C.C., Korbet, S.M., Lewis, E.J., Schwartz, M.M., Reichlin, M. and Evans, J. (2001) Significance of Histologic Patterns of Glomerular Injury Upon Long-Term Prognosis in Severe Lupus Glomerulonephritis. Kidney International, 59, 2156-2163. https://doi.org/10.1046/j.1523-1755.2001.00730.x

[101] Sloan, R.P., Schwartz, M.M., Korbet, S.M. and Borok, R.Z. (1996) Long-Term Outcome in Systemic Lupus Erythematosus Membranous Glomerulonephritis. Lupus Nephritis Collaborative Study Group. Journal of the American Society of Nephrology, 7, 299-305. https://doi.org/10.1681/ASN.V72299

[102] Liu, C.B., Hu, W.X., Xie, H.L., Zhang, H.T., Chen, H.P., Zeng, C.H., Liu, Z.H., Li, L.S. (2006) Mycophenolate Mofetil versus Intravenous Pulse Cyclophosphamide for Class IV Plus V Lupus Nephritis. Chin Nephrol Dial Transplant, 15, 1-6.

[103] Zhang, H.T., Hu, W.X., Xie, H.L., Zeng, C.H., Chen, H.P., Liu, Z.H. and Li, L.S. (2006) Randomized Controlled Trial of Tacrolimus versus Intravenous Cyclophos- 
phamide in the Induction Therapy of Class V Plus IV Lupus Nephritis. Chin Nephrol Dial Transplant, 15, 508-514.

[104] Sun, Q., Liu, Z.H., Cheng, Z., Chen, J., Ji, S., Zeng, C. and Li, L.S. (2007) Treatment of Early Mixed Cellular and Humoral Renal Allograft Rejection with Tacrolimus and Mycophenolate Mofetil. Kidney International, 71, 24-30.

https://doi.org/10.1038/sj.ki.5001870

[105] Weening, J.J., D’Agati, V.D., Schwartz, M.M., Seshan, S.V., Alpers, C.E., Appel, G.B., et al. (2004) The Classification of Glomerulonephritis in Systemic Lupus Erythematosus Revisited. Journal of the American Society of Nephrology, 15, 241-250. https://doi.org/10.1097/01.ASN.0000108969.21691.5D

[106] Holdsworth, S.R., Kitching, A.R. and Tipping, P.G. (1999) Th1 and Th2 T Helper Cell Subsets Affect Patterns of Injury and Outcomes in Glomerulonephritis. Kidney International, 55, 1198-1216. https://doi.org/10.1046/j.1523-1755.1999.00369.x

[107] El Hachmi, M., Jadoul, M., Lefebvre, C., Depresseux, G. and Houssiau, F.A. (2003) Relapses of Lupus Nephritis: Incidence, Risk Factors, Serology and Impact on Outcome. Lupus, 12, 692-696.

[108] Mok, C.C., Ying, K.Y., Tang, S., Leung, C.Y., Lee, K.W., Ng, W.L., Wong, R.W. and Lau, C.S. (2004) Predictors and Outcome of Renal Flares after Successful Cyclophosphamide Treatment for Diffuse Proliferative Lupus Glomerulonephritis. Arthritis \& Rheumatism, 50, 2559-2568. https://doi.org/10.1002/art.20364

[109] Kobau, R., Sniezek, J., Zack, M.M., Lucas, R.E. and Burns, A. (2010) Well-Being Assessment: An Evaluation of Well-Being Scales for Public Health and Population Estimates of Well-Being among U.S. Adults. Applied Psychology: Health and Well-Being, 2, 272-297. https://doi.org/10.1111/j.1758-0854.2010.01035.x

[110] Healthy People (2020) Healthy People 2020 Framework. The Vision, Mission, and Goals of Healthy People 2020. Overarching Goals.

http://healthypeople.gov/2020/Consortium/HP2020Framework

[111] Healthy People (2020) About Healthy People. Foundation Health Measures. http://healthypeople.gov/2020/about/QoLWBabout.aspx

[112] World Health Organization (1946) Constitution of the World Health Organization. http://www.who.int/governance/eb/who_constitution_en.pdf

[113] World Health Organization (2005) The World Health Organization Quality of Life Assessment (WHOQOL): Position Paper from the World Health Organization. Social Science \& Medicine, 41, 1403-1409.

https://doi.org/10.1016/0277-9536(95)00112-K

[114] Ferrans, C.E. (2005) Definitions and Conceptual Models of Quality of Life. In: Lipscomb, J., Gotay, C.C. and Snyder, C., Eds., Outcomes Assessment in Cancer, Cambridge University, Cambridge, 14-30. https://doi.org/10.1017/CBO9780511545856.002

[115] Adamichou, C. and Bertsias, G. (2017) Flares in Systemic Lupus Erythematosus: Diagnosis, Risk Factors and Preventive Strategies. Mediterranean Journal of Rheumatology, 28, 4-12.

[116] CDC (Centers for Disease Control and Prevention) (2000) Measuring Healthy Days: Population Assessment of Health-Related Quality of Life. Centers for Disease Control and Prevention, Atlanta.

[117] Cella, D., Yount, S., Rothrock, N., Gershon, R., Cook, K., Reeve, B., Ader, D., Fries, J. F., Bruce, B. and Matthias, R., on behalf of the PROMIS Cooperative Group (2007) The Patient Reported Outcomes Measurement Information System (PROMIS): Progress of an NIH Roadmap Cooperative Group during Its First Two Years. Med- 
ical Care, 45, S3-S11. https://doi.org/10.1097/01.mlr.0000258615.42478.55

[118] Cella, D., Riley, W., Stone, A., Rothrock, N., Reeve, B., Yount, S., Amtmann, D., Bode R., Buysse D., Choi, S., Cook, K., DeVellis, R., DeWalt, D., Fries, J.F., Gershon, R., Hahn, E.A., Lai, J. S., Pilkonis, P., Revicki, D., Rose, M., Weifurt K. and Hays, R., on behalf of the PROMIS Cooperative Group (2010) Initial Adult Health Item Banks and First Wave Testing of the Patient-Reported Outcomes Measurement Information System (PROMIS) Network: 2005-2008. Journal of Clinical Epidemiology, 63, 1179-1194. https://doi.org/10.1016/j.jclinepi.2010.04.011

[119] Jolly, M., Toloza, S., Bertoli, A., Blazevic, I., Vila, L., Moldovan, I., et al. (2014) FRI0398 Disease Specific Quality of Life in Patients with Lupus Nephritis. Annals of Rheumatic Diseases, 73, Article No. 531. https://doi.org/10.1136/annrheumdis-2014-eular.3775

[120] Chessa, E., Piga, M., Floris, A., Devilliers, H., Cauli, A. and Arnaud, L. (2020) Use of Physician Global Assessment in Systemic Lupus Erythematosus: A Systematic Review of Its Psychometric Properties. Rheumatology, 59, 3622-3632. https://doi.org/10.1093/rheumatology/keaa383

[121] Mikdashi, J. and Nived, O. (2015) Measuring Disease Activity in Adults with Systemic Lupus Erythematosus: The Challenges of Administrative Burden and Responsiveness to Patient Concerns in Clinical Research. Arthritis Research \& Therapy, 17, Article No. 183.

[122] Van Vollenhoven, R., Voskuyl, A., Bertsias, G., Aranow, C., Aringer, M., et al. (2017) A Framework for Remission in SLE: Consensus Findings from a Large International Task Force on definitions of Remission in SLE (DORIS). Annals of the Rheumatic Diseases, 76, 554-561. https://doi.org/10.1136/annrheumdis-2016-209519

[123] van Vollenhoven, R.F., Mosca, M., Bertsias, G., Isenberg, D., Kuhn, A., Lerstrøm, K., et al. (2014) Treat-to-Target in Systemic Lupus Erythematosus: Recommendations from an International Task Force. Annals of the Rheumatic Diseases, 73, 958-967. https://doi.org/10.1136/annrheumdis-2013-205139

[124] Medina-Quinones, C.V., Ramos-Merino, L., Ruiz-Sada, P. and Isenberg, D. (2016) Analysis of Complete Remission in Systemic Lupus Erythematosus Patients over a 32-Year Period. Arthritis Care \& Research, 68, 981-987. https://doi.org/10.1002/acr.22774

[125] Steiman, A.J., Urowitz, M.B. Ibanez, D., Papneja, A. and Gladman, D.D. (2014) Prolonged Clinical Remission in Patients with Systemic Lupus Erythematosus. The Journal of Rheumatology, 41, 1808-1816. https://doi.org/10.3899/jrheum.131137

[126] Ugarte-Gil, M.F., Wojdyla, D., Pons-Estel, G.J., Catoggio, L.J., Drenkard, C., Sarano, J., et al. (2017) Remission and Low Disease Activity Status (LDAS) Protect Lupus Patients from Damage Occurrence: Data from a Multiethnic, Multinational Latin American Lupus Cohort (GLADEL). Annals of the Rheumatic Diseases, 76, 2071-2074. https://doi.org/10.1136/annrheumdis-2017-211814

[127] Urowitz, M.B., Feletar, M., Bruce, I.N., Ibañez, D. and Gladman, D.D. (2005) Prolonged Remission in Systemic Lupus Erythematosus. Journal of Rheumatology, 32, 1467-1472.

[128] Zen, M., Iaccarino, L., Gatto, M., Bettio, S., Nalotto, L., Ghirardello, A., et al. (2015) Prolonged Remission in Caucasian Patients with SLE: Prevalence and Outcomes. Annals of the Rheumatic Diseases, 74, 2117-2122. https://doi.org/10.1136/annrheumdis-2015-207347

[129] Tsang-A-Sjoe, M.W.P., Bultink, I.E.M., Heslinga, M. and Voskuyl, A.E. (2017) Both 
Prolonged Remission and Lupus Low Disease Activity State Are Associated with Reduced Damage Accrual in Systemic Lupus Erythematosus. Rheumatology, 56, 121-128. https://doi.org/10.1093/rheumatology/kew377

[130] Zen, M., Iaccarino, L., Gatto, M., Saccon, F., Larosa, M., Ghirardello, A., et al. (2018) Lupus Low Disease Activity State Is Associated with a Decrease in Damage Progression in Caucasian Patients with SLE, but Overlaps with Remission. Annals of the Rheumatic Diseases, 77, 104-110.

https://doi.org/10.1136/annrheumdis-2017-211613

[131] Polachek, A., Gladman, D.D., Su, J. and Urowitz, M.B. (2017) Defining Low Disease Activity in Systemic Lupus Erythematosus. Arthritis Care \& Research, 69, 997-1003. https://doi.org/10.1002/acr.23109

[132] Tselios, K., Gladman, D.D., Touma, Z., Su, J., Anderson, N. and Urowitz, M.B. (2019) Clinical Remission and Low Disease Activity Have Comparable Outcomes over 10 Years in Systemic Lupus Erythematosus. Arthritis Care \& Research, 71, 822-828. https://doi.org/10.1002/acr.23720

[133] Ruperto, N., Hanrahan, L.M., Alarcón, G.S., Belmont, H.M., Brey, R.L., Brunetta, P. et al. (2011) International Consensus for a Definition of Disease Flare in Lupus. Lupus, 20, 453-462. https://doi.org/10.1177\%2F0961203310388445

[134] Koutsonikoli, A., Trachana, M., Heidich, A.-B., Galanopoulou, V., Pratsidou-Gertsi, P. and Garyphallos, A. (2015) Dissecting the Damage in Northern Greek Patients with Childhood-Onset Systemic Lupus Erythematosus: A Retrospective Cohort Study. Rheumatology International, 35, 1225-1232. https://doi.org/10.1007/s00296-014-3209-6

[135] Ines, L., Duarte, C., Silva, R.S., Teixeira, A.S., Fonseca, F.P. and da Silva, J.A. (2014) Identification of Clinical Predictors of Flare in Systemic Lupus Erythematosus $\mathrm{Pa}$ tients: A 24 Month Pros-Pective Cohort Study. Rheumatology, 53, 85-89. https://doi.org/10.1093/rheumatology/ket322

[136] Fanouriakis, A., Kostopoulou, M., Alunno, A., Aringer, M., Bajema, I., Boletis, J.N., et al. (2019) 2019 Update of the EULAR Recommendations for the Management of Systemic Lupus Erythematosus. Annals of the Rheumatic Diseases, 78, 736-745. https://doi.org/10.1136/annrheumdis-2019-215089

[137] Elkayam, O., On Behalf of Eular Task Force (2018) SP0158 Update of EULAR Recommendations for Vaccination of Patients with Autoimmune Inflammatory Rheumatic Diseases. Annals of the Rheumatic Diseases, 77, Article No. 41. https://doi.org/10.1136/annrheumdis-2018-eular.7622

[138] van Assen, S., Agmon-Levin, N., Elkayam, O., Cervera, R., Doran, M.F., Dougados, M., et al. (2011) EULAR Recommendations for Vaccination in Adult Patients with Autoimmune Inflammatory Rheumatic Diseases. Annals of the Rheumatic Diseases, 70, 414-422. https://doi.org/10.1136/ard.2010.137216

[139] Seymour, C.W., Liu, V.X., Iwashyna, T.J., Brunkhorst, F.M., Rea, T.D., Scherag, A., et al. (2016) Assessment of Clinical Criteria for Sepsis: For the Third International Consensus Definitions for Sepsis and Septic Shock (Sepsis-3). JAMA, 315, 762-774. https://doi.org/10.1001/jama.2016.0288

[140] Ballocca, F., D’Ascenzo, F., Moretti, C., Omedè, P., Cerrato, E., Barbero, U., et al. (2015) Predictors of Cardiovascular Events in Patients with Systemic Lupus Erythematosus (SLE): A Systematic Review and Meta Analysis. European Journal of Preventive Cardiology, 22, 1435-1441. https://doi.org/10.1177/2047487314546826

[141] Magder, L.S. and Petri, M. (2012) Incidence of and Risk Factors for Adverse Cardiovascular Events among Patients with Systemic Lupus Erythematosus. American 
Journal of Epidemiology, 176, 708-719.

https://doi.org/10.1093/aje/kws130

[142] Wu, G.-C., Liu, H.-R., Leng, R.-X., Li, X.-P., Li, X.-M., Pan, H.-F., et al. (2016) Subclinical Atherosclerosis in Patients with Systemic Lupus Erythematosus: A Systemic Review and Meta-Analysis. Autoimmunity Reviews, 15, 22-37.

https://doi.org/10.1016/j.autrev.2015.10.002

[143] Gustafsson, J.T. and Svenungsson, E. (2014) Definitions of and Contributions to Cardiovascular Disease in Systemic Lupus Erythematosus. Autoimmunity, 47, 67-76. https://doi.org/10.3109/08916934.2013.856005

[144] Gaziano, J.M., Brotons, C., Coppolecchia, R., Cricelli, C., Darius, H., Gorelick, P.B., et al. (2018) Use of Aspirin to Reduce Risk of Initial Vascular Events in Patients at Moderate Risk of Cardiovascular Disease (ARRIVE): A Randomized, Double-Blind, Placebo-Controlled Trial. Lancet, 392, 1036-1046. https://doi.org/10.1016/S0140-6736(18)31924-X

[145] https://www.mayoclinic.org/diseases-conditions/lupus-nephritis/diagnosis-treatme nt/drc-20446438 


\section{Appendix: Flowchart Detailing the Work Plan}

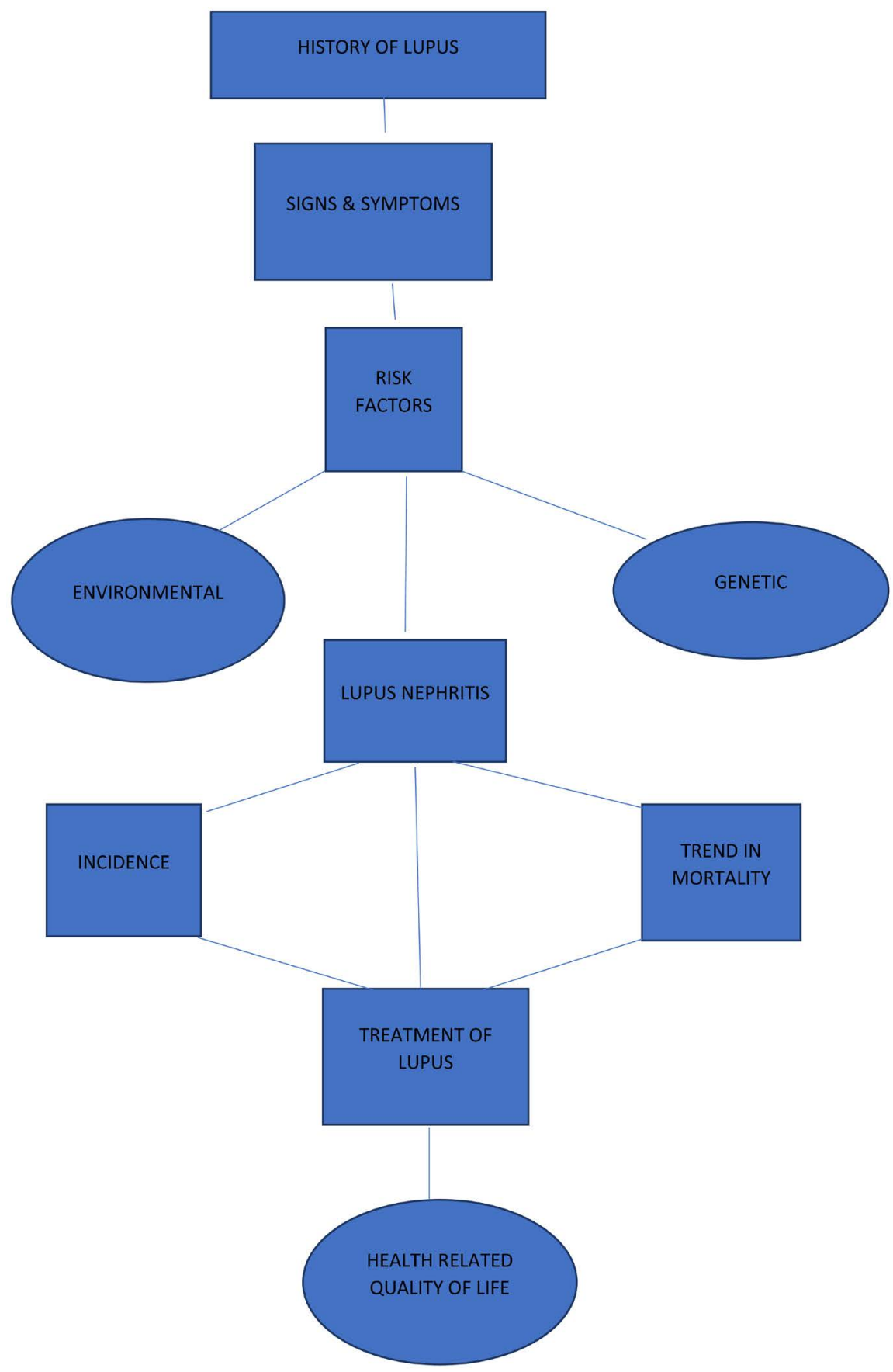

